\title{
BALANÇO SOCIAL: UMA ANÁLISE COMPARATIVA DOS INDICADORES SOCIAIS INTERNOS E EXTERNOS DAS INSTITUIÇÕES FINANCEIRAS CAIXA E BANCO DO BRASIL 2002 A 2011
}

\author{
Anderson Pires dos Santos ${ }^{1}$ \\ Luciênio Rosa e Silva Júnior ${ }^{2}$
}

\begin{abstract}
RESUMO
O objetivo do artigo é demonstrar os volumes e evolução dos indicadores sociais internos e externos das instituições financeiras Caixa e Banco do Brasil. O crescente avanço no setor econômico-financeiro e a evolução da ciência contábil, o balanço social é uma ferramenta auxiliadora e imprescindível na divulgação de informações sociais. Trata-se de um estudo descritivo, com abordagem qualitativa. A coleta de dados deu-se através das web-páginas das instituições financeiras buscando informações nos seus relatórios de sustentabilidade. A problemática que a pesquisa buscou investigar é o volume e a evolução dos investimentos sociais realizados nos Indicadores Sociais Internos e Externos das Instituições Financeiras Caixa e Banco do Brasil, com base no Balanço Social de 2002 a 2011. As principais análises sinalizam que $6,56 \%$ e $9,66 \%$ da receita líquida total do período analisado foram absorvidos pelos investimentos sociais internos para a Caixa e Banco do Brasil, respectivamente. Quanto aos investimentos sociais externos, absorveram 3,09\% para a Caixa e 6,53\% para o Banco do Brasil em relação à receita líquida do período analisado. Os componentes com maiores investimentos são encargos sociais compulsórios, participação nos lucros e resultados e alimentação, isso no ambiente interno e nesta mesma ordem para a Caixa e Banco do Brasil. No ambiente externo, para a Caixa são cultura e esporte, e o Banco do Brasil, combate à fome e segurança alimentar e cultura, conforme o período analisado.
\end{abstract}

Palavras-chave: Balanço Social, Instituições Financeiras, Responsabilidade Social, Indicadores Sociais.

\section{INTRODUÇÃ̃O}

No Brasil, as instituições financeiras são o alicerce de todo o sistema financeiro nacional, sendo referência de transparência e eficiência. E neste ambiente a Caixa e o Banco do Brasil, são instituições que sustentam uma parcela significativa, através de iniciativas que visam proporcionar uma oportunidade de vida melhor, entendem que estas iniciativas são demandas da sociedade, obrigações da cidadania e marca das empresas responsáveis. (FEBRABAN, 2012).

A Caixa e o Banco do Brasil mantêm padrões éticos aceitos pela sociedade, considerando que tal conceito é relevante, destaca-se que o referencial de gestão que permeia apenas a lucratividade financeira nas transações contraria as perspectivas atuais do mercado, que a cada dia precisam de empresas que pautem suas relações em princípios éticos,

\footnotetext{
${ }^{1}$ Acadêmico de Ciências Contábeis da UNEMAT.

${ }^{2}$ Professor de Ciências Contábeis da UNEMAT, campus de Tangará da Serra. 
Balanço social: uma análise comparativa dos indicadores sociais internos e externos das instituições financeiras Caixa e Banco do Brasil 2002 a 2011

Anderson Pires dos Santos, Luciênio Rosa e Silva Júnior

alinhando crescimento econômico, inclusão social e conservação do meio ambiente (FEBRABAN, 2012).

Neste cenário, estas instituições e todo o conglomerado financeiro acredita que a responsabilidade social está associada ao reconhecimento de que as decisões e os resultados das atividades das companhias alcançam um universo de agentes sociais muito mais amplo do que o composto por seus sócios e acionistas, enfatiza o impacto das atividades das empresas para os agentes com os quais interagem. Para o desempenho dessas entidades é necessário que envolva responsabilidade e dignidade junto aos blocos sociais onde se encontra inserida. (BNDES, 2000).

O exercício desempenhado pelas instituições financeiras Caixa e Banco do Brasil acerca da responsabilidade social é visualizar um desenvolvimento e distribuição de renda igualitária e é sem dúvida a maneira pela qual as instituições e o governo podem medir o clima organizacional e ambiental. Além das exigências do mercado altamente competitivo, as entidades objetivam desenvolver seus produtos respeitando o meio ambiente, princípio este, essencial para o atendimento da responsabilidade social (BANCO DO BRASIL e CAIXA, 2012). Conforme Tinoco (2006) é através de balanços sociais e relatórios que justificam suas parcelas investidas na sociedade.

O uso consciente das disponibilidades das entidades implica no bom resultado e desenvolvimento da sociedade, não mais é suficiente ter lucro, deve-se distribuir, repassar e investir parcelas que contribuam ao crescimento sustentável da sociedade e do meio que estão inseridas (BANCO DO BRASIL, 2012). A sustentabilidade deve estar inserida na visão e objetivos das entidades, satisfazendo os ideais esperados pela sociedade. Nesta perspectiva, o problema proposto foi: Qual o volume e a evolução dos investimentos sociais realizados nos Indicadores Sociais Internos e Externos das Instituições Financeiras Caixa e Banco do Brasil, com base nos Balanços Sociais no período de 2002 a 2011 ?

Para tanto, o objetivo geral desta pesquisa é demonstrar os indicadores sociais internos e externos, comparando seus volumes e evolução. Sua temática específica é a:

Comparar os valores e volumes investidos nestas instituições.

Analisar os componentes com maiores investimentos no período. 
Balanço social: uma análise comparativa dos indicadores sociais internos e externos das instituições financeiras Caixa e Banco do Brasil 2002 a 2011

Anderson Pires dos Santos, Luciênio Rosa e Silva Júnior

\section{REFERENCIAL TEÓRICO}

\subsection{Responsabilidade Social}

A observância quanto aos aspectos socioambientais na atualidade justificam-se sua necessidade no sentido de atender e objetivar o crescimento racional, cada setor ou empresa deve devolver à sociedade parcelas que contribuem para o melhoramento e evolução do meio ambiente e das questões sociais. Está cada vez mais difundida, nos vários setores da sociedade, a ideia de que a atual situação do mundo requer atenção especial das empresas para sua dimensão social. A dimensão delas não restringe apenas a determinada sociedade, cidade ou país, mas ao modo com que se organiza e principalmente atua, por meio de atividades essenciais (SILVA; FREIRE, 2001).

Consiste em gerar renda e emprego, distribuídos de forma mais equitativa a todos os envolvidos em sua geração, propiciando oportunidades àqueles que estão afastados de seus postos de trabalho e do mercado, especialmente nos países denominados de terceiro mundo, particularmente o Brasil. Conforme Tinoco (2006) as entidades devem manter transparência em todas as suas manifestações, seja na contratação de um funcionário ao relacionamento com um fornecedor. Suas perspectivas lançadas devem trazer objetividade e clareza a respeito do meio social e ambiental.

O conceito de responsabilidade social está associado ao reconhecimento de que as decisões e os resultados das atividades das companhias alcançam um universo de agentes social muito mais amplo do que o composto por seus sócios e acionistas, enfatiza o impacto das atividades das empresas para os agentes com os quais interagem, empregados, clientes, fornecedores, colaboradores, governos e comunidade. Permeia a sociedade e a encaminha com ideias que segurarão as próximas gerações (BNDES, 2000).

Responsabilidade social empresarial pode ser ainda definida como a forma de gestão que se define pela relação ética e transparente da empresa com todos os públicos com os quais ela se relaciona e pelo estabelecimento de objetivos empresariais que acelerem o desenvolvimento sustentável da sociedade, preservando recursos ambientais e culturais para as gerações futuras, respeitando a diversidade e promovendo a redução das desigualdades sociais. (INSTITUTO ETHOS, 2012)

\subsection{Balanço Social}

Segundo Silva e Freire (2001), balanço social é "um instrumento colocado na mão de empresários para que possam refletir, medir, sentir como vai tal empresa, o seu Revista UNEMAT de Contabilidade 
Balanço social: uma análise comparativa dos indicadores sociais internos e externos das instituições financeiras Caixa e Banco do Brasil 2002 a 2011

Anderson Pires dos Santos, Luciênio Rosa e Silva Júnior

empreendimento no campo social". Evidencia os fatos sociais inerentes a empresa, interno e externo, sua cultura e crescimento depende dos investimentos e retornos que devolvem a sociedade

Os estudos mais recentes das relações da entidade com o ambiente ajudaram a conceber um conceito de balanço social que traduzisse de maneira literal sua dimensão como instrumento analítico capaz de identificar situações nas quais é necessário ter em conta a série de efeitos que sintetizam a expressão responsabilidade social da entidade. Esse instrumento é o balanço social, (TINOCO, 2006). Nota-se que seu significado e dimensão é universal, mostra objetivamente os recursos disponibilizados para a sociedade em forma de investimentos no âmbito social e ambiental, possui características que tornam as empresas socioambientalmente responsáveis.

Em meados da década de 60 notavam-se no Brasil as tendências para a responsabilidade social, mas somente no regime militar na década de 70 , que surgiu a primeira marca de responsabilidade social partindo do governo como exigência das empresas de apresentarem uma relação social de seus funcionários. "Os anos 80 foram marcados pelo esgotamento do modelo de desenvolvimento instaurado no pós-guerra, cujo desdobramento ao longo de quatro décadas - dos anos 40 aos anos 70 - se deu sob a égide de um Estado altamente interveniente. (SILVA, FREIRE: 2001).

A partir de 1993, empresas de diversos setores passaram a realizar, anos após ano, efetivas ações sociais e ambientais, ao mesmo tempo em que começaram a divulgar de maneira ostensiva - inclusive nos meios de comunicação - um perfil mais social e humano dessas corporações. Assim, foi no início dos anos 90 que a realização anual de relatórios sociais e ambientais entra num amplo processo de aceitação e disseminação no meio empresarial. (SILVA, FREIRE: 2001).

No entanto, só ganhou visibilidade nacional quando o sociólogo Herbert de Souza, o Betinho, lançou, em junho de 1997, uma campanha pela divulgação voluntária do balanço social. Com o apoio e a participação de lideranças empresariais, a campanha decolou e vem suscitando uma série de debates através da mídia, seminários e fóruns. Hoje é possível contabilizar o sucesso desta iniciativa e afirmar que o processo de construção de uma nova mentalidade e de novas práticas no meio empresarial está em pleno curso. (BALANÇO SOCIAL, 2012).

A ideia do Balanço Social é demonstrar quantitativamente e qualitativamente o papel desempenhado pelas empresas no ambiente social, tanto internamente quanto na sua atuação na comunidade e com seus parceiros. Os itens da verificação quanto à responsabilidade são 
Balanço social: uma análise comparativa dos indicadores sociais internos e externos das instituições financeiras Caixa e Banco do Brasil 2002 a 2011

Anderson Pires dos Santos, Luciênio Rosa e Silva Júnior

vários, destacando a educação, saúde, atenção à mulher, atuação na preservação do meio ambiente, melhoria na qualidade de vida e de trabalho de seus empregados, apoio a projetos comunitários visando à erradicação da pobreza, geração de renda e de novos postos de trabalho, dentre outros. O campo é vasto e diversas empresas estão trilhando esse caminho. "Realizar o Balanço Social significa uma grande contribuição para consolidação de uma sociedade verdadeiramente democrática." (BALANÇO SOCIAL, 2012).

\subsubsection{Balanço Social - modelo IBASE}

O modelo IBASE do Instituto Brasileiro de Análises Sociais e Econômicas é um balanço similar ao notório balanço patrimonial das entidades, porém, é delimitador e possui cunho social, apresenta apenas informações socioambientais realizados pelas entidades. No entanto, esse modelo alcançou certa popularidade entre as empresas dado a facilidade de sua elaboração. Acentua ainda, informações quantitativo-financeiras e deve ser publicado com dados do ano presente e do ano anterior para permitir a comparabilidade (LANZARIN, 2011).

Esse modelo é dividido em critérios que agrupam determinados tipos de informações como apresentado no quadro abaixo.

Quadro 1- Divisões do modelo IBASE de Balanço Social

\begin{tabular}{|l|l|}
\hline \multicolumn{1}{|c|}{ Seção } & \multicolumn{1}{c|}{ Componentes } \\
\hline Base de Cálculo & $\begin{array}{l}\text { Receita líquida, Resultado operacional e Folha de pagamento } \\
\text { bruta. }\end{array}$ \\
\hline $\begin{array}{l}\text { Indicadores Sociais } \\
\text { Internos }\end{array}$ & $\begin{array}{l}\text { Alimentação, Saúde, Previdência privada, Educação, Cultura, } \\
\text { Auxílios-creche, Saúde e Segurança do trabalho. }\end{array}$ \\
\hline $\begin{array}{l}\text { Indicadores Sociais } \\
\text { Externos }\end{array}$ & $\begin{array}{l}\text { Educação, Cultura, Saúde, Saneamento, Esporte, Combate à } \\
\text { fome na comunidade, Subsídios e patrocínios a programas de } \\
\text { inclusão social. }\end{array}$ \\
\hline Indicadores Ambientais & $\begin{array}{l}\text { Investimentos de preservação e recuperação do meio ambiente } \\
\text { ligados ou não às atividades da empresa. }\end{array}$ \\
\hline $\begin{array}{l}\text { Indicadores do Corpo } \\
\text { Funcional }\end{array}$ & $\begin{array}{l}\mathrm{N}^{\circ} \text { total de empregados, de admissões, de empregados } \\
\text { terceirizados, de estagiários, de empregados com mais de 45 } \\
\text { anos, de mulheres e de negros bem como os percentuais de } \\
\text { cargos de chefia ocupados por mulheres e negros. }\end{array}$ \\
\hline $\begin{array}{l}\text { Exercício da Cidadania } \\
\text { Empresarial }\end{array}$ & $\begin{array}{l}\text { Comparativo da gestão cidadã ocorrida e estimativas para o } \\
\text { exercício seguinte. }\end{array}$ \\
\hline Outras Informações & Todas as outras informações relevantes \\
\hline
\end{tabular}

Fonte: IBASE - Instituto Brasileiro de Análises Sociais e Econômicas - 2012 
Balanço social: uma análise comparativa dos indicadores sociais internos e externos das instituições financeiras Caixa e Banco do Brasil 2002 a 2011

Anderson Pires dos Santos, Luciênio Rosa e Silva Júnior

\subsubsection{Indicadores Sociais - IBASE}

O balanço social é elaborado segundo a metodologia do IBASE, apresenta dados e informações de dois exercícios anuais por meio de uma tabela bastante simples e direta, que deve ser publicada e amplamente divulgada. O modelo atual é composto por 43 indicadores quantitativos e oito indicadores qualitativos, organizados em sete categorias. Como o objetivo do trabalho é analisar somente os indicadores sociais internos e externos, iremos defini-los para melhor esclarecimento e entendimento (BALANÇO SOCIAL, 2012).

Indicadores sociais internos - Nesta parte do balanço são apresentados todos os investimentos internos, obrigatórios e voluntários, que a empresa realiza para beneficiar e/ou atender ao corpo funcional (alimentação, encargos sociais compulsórios, previdência privada, saúde, segurança e medicina no trabalho, educação, cultura, capacitação e desenvolvimento profissional, creches ou auxílio-creche, participação nos lucros ou resultados e outros). (BALANÇO SOCIAL, 2012).

Indicadores sociais externos - Aqui aparecem os investimentos voluntários da empresa, cujo público-alvo é a sociedade em geral (projetos e iniciativas nas áreas de educação, cultura, saúde e saneamento, esporte, combate à fome e segurança alimentar, pagamento de tributos e outros). São as ações sociais privadas realizadas por empresas visando à sociedade ou a alguma comunidade externa relacionada, direta ou indiretamente, com os objetivos ou interesses das corporações. (BALANÇO SOCIAL, 2012).

\subsection{Investimentos Sociais pelas Instituições Financeiras}

Instituições financeiras são entidades que representam a base do sistema monetário brasileiro. Subdivididas em bancos comerciais, de investimentos, desenvolvimento, múltiplos, cooperativos e Caixas econômicas (NEWLANDS JUNIOR, 2010).

Segundo a FEBRABAN - Federação Brasileira de Bancos (2012), As instituições financeiras revelam seu compromisso com as comunidades por meio do desenvolvimento e apoio a uma série de projetos sociais e culturais, coordena um conjunto de projetos sociais, conduzidos pelas instituições associadas, para contribuir com a melhoria da qualidade de vida dos profissionais das instituições e das comunidades do entorno. Sua presença na sociedade e investimentos permeiam a sensibilidade do social e o capitalismo.

Um sistema financeiro saudável, ético e eficiente é condição essencial para o desenvolvimento econômico, social e sustentável do país. Desenvolvem uma série de iniciativas que procuram proporcionar a milhões de brasileiros uma condição melhor, um ambiente melhor, uma oportunidade de vida melhor. Entendem que essas iniciativas no 
Balanço social: uma análise comparativa dos indicadores sociais internos e externos das instituições financeiras Caixa e Banco do Brasil 2002 a 2011

Anderson Pires dos Santos, Luciênio Rosa e Silva Júnior

campo da sustentabilidade são demandas da sociedade, obrigações da cidadania e marca das empresas responsáveis. (FEBRABAN, 2012).

Ao oferecer e receber serviços, empregar pessoas e relacionar-se com outras organizações, parceiros e comunidades, uma empresa deve ser vista, acima de tudo, como um ente vivo e social, mantendo padrões éticos aceitos pela sociedade. Considerando-se tal conceito, é relevante destacar que o referencial de gestão que prega apenas a lucratividade financeira do negócio contraria as perspectivas atuais do mercado, que hoje pede empresas que pautem suas relações em princípios éticos, combinando crescimento econômico, inclusão social e a conservação do meio ambiente. (FEBRABAN, 2012).

Essa modalidade de gestão é alicerçada nos princípios da Responsabilidade Social Empresarial (RSE), que busca garantir objetivos empresariais compatíveis com o desenvolvimento sustentável da sociedade, preservando recursos ambientais e culturais para as gerações futuras, respeitando a diversidade e promovendo a redução das desigualdades sociais. (CAIXA, 2012).

\section{$1 \quad$ Histórico Caixa e Banco do Brasil}

A CAIXA foi criada em 12 de janeiro de 1861 pelo imperador Pedro II com a finalidade de conceder empréstimos e incentivar a poupança. O objetivo era torna-la o "cofre seguro das classes menos favorecidas", nas palavras do Visconde de Rio Branco. Seu nome de batismo foi Caixa Econômica Federal e Monte de Socorro. É uma instituição financeira sob a forma de empresa pública que atua em todo o território nacional e integra o Sistema Financeiro Nacional.

Vinculada ao Ministério da Fazenda, auxilia a política de crédito do Governo Federal e está sujeita às decisões e à disciplina normativa do órgão competente e à fiscalização do Banco Central do Brasil. Desde então vem investindo e disponibilizando recursos à sociedade com a premissa de crescimento e desenvolvimento social em âmbito nacional. (CAIXA, 2012)

Sua máxima é colaborar com o crescimento do país, mantendo uma relação ética e transparente com todos os agentes que se relaciona e estabelece metas empresariais compatíveis com o desenvolvimento sustentável da sociedade. É caracterizada por empresa social, pois desenvolve políticas do governo federal no cenário social e disponibiliza recursos para investimentos urbanos, conforme consta de seu estatuto social. Atua no setor financeiro sujeita à dinâmica de fatores de mercado e às diretrizes da política pública do Governo 
Balanço social: uma análise comparativa dos indicadores sociais internos e externos das instituições financeiras Caixa e Banco do Brasil 2002 a 2011

Anderson Pires dos Santos, Luciênio Rosa e Silva Júnior

Federal, especialmente aquelas destinadas ao desenvolvimento urbano e transferência de benefícios. (CAIXA, 2012).

A exemplo dos Relatórios de Administração, de Gestão e das Demonstrações de Resultados da empresa, publicados na imprensa e disponibilizados no site www.Caixa.gov.br, a CAIXA divulga seu Balanço Social, com as ações que consolidam seu compromisso com a sociedade brasileira e com os preceitos do Pacto Global de Responsabilidade Social, iniciativa da Organização das Nações Unidas - ONU, do qual a CAIXA é signatária. Por sua natureza de empresa pública, a CAIXA, como executora das políticas do Governo Federal, tem sua imagem associada aos princípios de responsabilidade social (CAIXA, 2012).

O Banco do Brasil, fundado em 1808, por determinação de D. João, inicia suas atividades auxiliando a família real nas diversas demandas da corte. No mesmo ano, por decreto de 3 de setembro, foi iniciada a emissão dos "escritos da Alfândega", conhecidos mais tarde por "bilhetes", que eram dados como pagamento nas estações públicas. O principal objetivo da fundação do Banco, era destacado na introdução dos documentos de fundação: proporcionar, com urgência, fundos para a manutenção da cúpula monárquica (BANCO DO BRASIL, 2012).

Sua missão permanece clara e objetiva, sustentando seus valores e princípios aos longos dos anos, desempenhando uma função política e pública de distribuição e investimentos de forma sustentável. Portanto, determina ser a solução em serviços e intermediação financeira, atender às expectativas de clientes e acionistas, fortalecer o compromisso entre os funcionários e a Empresa e contribuir para o desenvolvimento do País (BANCO DO BRASIL, 2012).

O Banco do Brasil, um dos principais conglomerados financeiros da América Latina, reforça sua preocupação com a sustentabilidade por meio da atuação comprometida com a rentabilidade dos negócios e com o planeta. O posicionamento sustentável permeia toda a empresa, da estrutura de negócios ao relacionamento com seus públicos. Na relação com seus públicos, preza pela equidade, pela transparência e pela oferta de informações de qualidade (BANCO DO BRASIL, 2012).

O sistema financeiro representa hoje a base da economia brasileira, com transparência e solidez é um dos melhores e mais confiáveis sistemas do mundo, com isso os bancos brasileiros são instituições que compõem a maior parte deste cenário. E neste ambiente a 
Balanço social: uma análise comparativa dos indicadores sociais internos e externos das instituições financeiras Caixa e Banco do Brasil 2002 a 2011

Anderson Pires dos Santos, Luciênio Rosa e Silva Júnior

Caixa e o Banco do Brasil são instituições que atuam e desenvolvem políticas sociais que somam aos diversos investimentos pelas demais instituições do sistema (FEBRABAN, 2012).

Os interesses quantos aos estudos acerca das informações sociais destas instituições favorecerá objetivos profissionais, permitirá conhecer os cenários e estes investimentos, suas evoluções e melhor entendimento. A exploração e explanação destas instituições é conhecer seus interesses e sua transparência com investimentos nesta área da sociedade, conforme eo Banco do Brasil e Caixa (2012), suas missões e objetivos é ser uma instituição social e transparente e para isso devem investir no cenário social o necessário para alcançarem tal objetivo.

\section{METODOLOGIA}

Esta pesquisa é descritiva, podendo ser classificada de acordo com seus objetivos e qualitativa, pois através da análise dos relatórios encontrados nas web-páginas das instituições financeiras e utilizando algumas ferramentas, fará a correlação de dados, comparação, análise vertical e demonstração da evolução dos balanços sociais. Para tanto, será utilizado planilhas eletrônicas para demonstrar os gráficos e análises encontrados.

Será realizada análises de comparação de documentos referentes aos investimentos sociais dos indicadores internos e externos das instituições financeiras Caixa e Banco do Brasil nos anos de 2002 a 2011. A técnica utilizada será levantamento de dados e a coleta de informações para a execução desta pesquisa será realizada via web-páginas das instituições financeiras. Para obter um resultado mais sólido e completo será utilizado todos os balanços sociais publicados das instituições. Para melhor interpretação e obtenção de informações reais, nos anos que tal instituição retificou o balanço social, os dados utilizados foram os corrigidos.

Conforme pesquisa realizada por Lanzarin (2011) com as instituições financeiras Itaú e Bradesco, as análises sustentam os mesmos parâmetros, os maiores investimentos são em encargos sociais, previdência privada e participação nos lucros ou resultados e apresentam sempre crescimento anual. 
Balanço social: uma análise comparativa dos indicadores sociais internos e externos das instituições financeiras Caixa e Banco do Brasil 2002 a 2011

Anderson Pires dos Santos, Luciênio Rosa e Silva Júnior

\section{RESULTADOS}

Em análise aos balanços sociais das instituições financeiras Caixa e Banco do Brasil as análises foram organizadas em tabelas e dividas por instituição para melhor visualização das informações e interpretação. As tabelas foram agrupadas por investimentos sociais internos e externos, demonstrando a relação dos investimentos com a receita líquida, análise vertical e a distribuição do montante dos investimentos aos componentes de cada indicador.

Para o alcance dos objetivos específicos desta pesquisa, foram utilizadas as Tabelas $1 \mathrm{a}$ 6, com percentuais, valores totais, componentes e as respectivas análises, inclusive a vertical para encontrar o componente com maior investimento.

\subsection{Investimentos Sociais Internos e Externos Instituição Caixa}

Tabela 01 - Proporções Receita Líquida/Investimentos Sociais Internos (em milhares)

\begin{tabular}{ccccc}
\hline $\boldsymbol{-}$ & $\mathbf{R L}$ & \multicolumn{1}{c}{ ISI } & ISI/RL & AV ISI \\
\hline 2002 & 25.757 .089 & 1.372 .169 & $5,33 \%$ & $5,02 \%$ \\
2003 & 31.999 .047 & 1.555 .217 & $4,86 \%$ & $5,70 \%$ \\
2004 & 27.353 .377 & 1.729 .889 & $6,32 \%$ & $6,33 \%$ \\
2005 & 34.231 .733 & 1.970 .538 & $5,76 \%$ & $7,22 \%$ \\
2006 & 38.556 .488 & 2.558 .409 & $6,64 \%$ & $9,37 \%$ \\
2007 & 41.207 .186 & 2.765 .451 & $6,71 \%$ & $10,13 \%$ \\
2008 & 42.708 .445 & 3.179 .693 & $7,45 \%$ & $11,64 \%$ \\
2009 & 47.749 .351 & 3.432 .743 & $7,19 \%$ & $12,57 \%$ \\
2010 & 54.700 .326 & 4.036 .438 & $7,38 \%$ & $14,78 \%$ \\
2011 & 71.866 .204 & 4.707 .342 & $6,55 \%$ & $17,24 \%$ \\
Total & $\mathbf{4 1 6 . 1 2 9 . 2 4 6}$ & $\mathbf{2 7 . 3 0 7 . 8 8 9}$ & $\mathbf{6 , 5 6 \%}$ & $\mathbf{1 0 0 , 0 0 \%}$ \\
\hline
\end{tabular}

Fonte: Dados da pesquisa

Conforme observa-se na Tabela 1, o volume dos investimentos sociais internos resultou em 27.307.889 milhares de reais, alcançando 6,56\% de toda sua receita líquida do período analisado, encontra pequenas evoluções ao longo dos anos, se analisados os valores investidos, no entanto, não manteve nenhuma tendência de crescimento em relação à proporção da receita, pois os investimentos não acompanharam a evolução da receita, como demonstrado.

Quanto à análise isolada dos investimentos sociais internos aplicando o método de análise vertical, logo obtém-se a evolução dos investimentos, pois a cada ano, a proporção do valor cresce em relação ao total encontrado e disponibilizado aos investimentos. Este 
Balanço social: uma análise comparativa dos indicadores sociais internos e externos das instituições financeiras Caixa e Banco do Brasil 2002 a 2011

Anderson Pires dos Santos, Luciênio Rosa e Silva Júnior

tratamento dos dados garante sua evolução no período e justifica as aplicabilidades ocorridas nos anos estudados.

Tabela 02 - Proporções Receita Líquida/Investimentos Sociais Externos (em milhares)

\begin{tabular}{ccccc}
\hline- & RL & ISE & ISE/RL & AV ISE \\
\hline 2002 & 25.757 .089 & 1.056 .786 & $4,10 \%$ & $8,23 \%$ \\
2003 & 31.999 .047 & 1.187 .367 & $3,71 \%$ & $9,25 \%$ \\
2004 & 27.353 .377 & 1.115 .418 & $4,08 \%$ & $8,69 \%$ \\
2005 & 34.231 .733 & 1.755 .802 & $5,13 \%$ & $13,67 \%$ \\
2006 & 38.556 .488 & 1.380 .435 & $3,58 \%$ & $10,75 \%$ \\
2007 & 41.207 .186 & 495.906 & $1,20 \%$ & $3,86 \%$ \\
2008 & 42.708 .445 & 1.084 .818 & $2,54 \%$ & $8,45 \%$ \\
2009 & 47.749 .351 & 1.920 .881 & $4,02 \%$ & $14,96 \%$ \\
2010 & 54.700 .326 & 1.014 .221 & $1,85 \%$ & $7,90 \%$ \\
2011 & 71.866 .204 & 1.830 .710 & $2,55 \%$ & $14,26 \%$ \\
Total & $\mathbf{4 1 6 . 1 2 9 . 2 4 6}$ & $\mathbf{1 2 . 8 4 2 . 3 4 4}$ & $\mathbf{3 , 0 9 \%}$ & $\mathbf{1 0 0 , 0 0 \%}$ \\
\hline
\end{tabular}

Fonte: Dados da Pesquisa

Os números dos investimentos sociais externos são desalinhados e sem conexão com a evolução da receita líquida, de acordo com a Tabela 2 e cada ano apresenta um percentual distante do ano anterior e posterior. O volume encontrado dos investimentos ocorridos no período analisado somam 12.842.344 milhares de reais, que correspondem a 3,09\% de toda a receita líquida obtida. Nota-se nos percentuais em relação à receita líquida que, os valores disponibilizados não evoluíram no decorrer do período, havendo apenas pequenos aumentos, porém, seguidos de queda. A análise vertical dessas informações comprova o texto já descrito, afirmando que não ocorreu nenhuma evolução se comparados à receita líquida, os anos analisados são marcados por distorções acerca dos valores investidos.

Tabela 3 - Análise dos Componentes ISI e ISE 2002-2012 (em milhares)

\begin{tabular}{lrc}
\hline Investimentos Sociais Internos & \multicolumn{1}{c}{ ISI } & AV \\
\hline Alimentação & 4.662 .217 & $17,07 \%$ \\
Encargos sociais compulsórios & 13.124 .107 & $48,06 \%$ \\
Previdência privada & 2.223 .388 & $8,14 \%$ \\
Saúde & 2.292 .319 & $8,39 \%$ \\
Segurança e medicina no trabalho & 67.130 & $0,25 \%$ \\
Educação & 157.691 & $0,58 \%$ \\
Cultura & 170.458 & $0,62 \%$ \\
Capacitação e desenvolvimento profissional & 453.080 & $1,66 \%$ \\
Creches ou auxílio-creche & 316.153 & $1,16 \%$ \\
\hline
\end{tabular}


Balanço social: uma análise comparativa dos indicadores sociais internos e externos das instituições financeiras Caixa e Banco do Brasil 2002 a 2011

Anderson Pires dos Santos, Luciênio Rosa e Silva Júnior

\begin{tabular}{lrc}
\hline Participação nos lucros ou resultados & 3.704 .572 & $13,57 \%$ \\
Outros & 146.126 & $0,54 \%$ \\
Total - Indicadores Sociais Internos & 27.307 .889 & $100,00 \%$ \\
& \multicolumn{2}{c}{} \\
Investimentos Sociais Externos & $\mathbf{I S E}$ & $\mathbf{A V}$ \\
Educação & 4.956 & $0,04 \%$ \\
Cultura & 308.433 & $2,40 \%$ \\
Saúde e Saneamento & 6.980 & $0,05 \%$ \\
Esporte & 270.571 & $2,11 \%$ \\
Combate à Fome e Segurança Alimentar & 10.670 & $0,08 \%$ \\
Outros & 1.105 & $0,01 \%$ \\
Total das Contribuições para Sociedade & 602.714 & $4,69 \%$ \\
Tributos (excluídos encargos sociais) & 12.239 .635 & $95,31 \%$ \\
Total - Indicadores Sociais Externos & $\mathbf{1 2 . 8 4 2 . 3 4 4}$ & $\mathbf{1 0 0 , 0 0 \%}$ \\
\hline
\end{tabular}

Fonte: Dados da pesquisa

Neste contexto de análises, demonstra os componentes dos investimentos sociais internos e externos e seus volumes individuais. Agora observamos quais os componentes com maior absorção do total disponibilizado para os investimentos no período de 2002 a 2012. Nos componentes internos, os encargos sociais compulsórios absorveram 48,06\%, do valor total dos investimentos sociais internos, dada a sua obrigatoriedade, apresentaremos outros componentes. A alimentação com 17,07\%, a participação nos lucros ou resultados de 13,52\% e saúde $8,39 \%$ da soma do montante dos investimentos internos.

Nos investimentos sociais externos, encontramos os encargos sociais excluídos com 95,31\% do valor investido total, no entanto, são desnecessários à análise dos objetivos da pesquisa, os componentes cultura e esporte, aparecem com os maiores percentuais $2,4 \%$ e $2,11 \%$, respectivamente.

\subsection{Investimentos Sociais Internos e Externos Instituição Banco do Brasil}

Tabela 04 - Proporções Receita Líquida/Investimentos Sociais Internos (em milhares)

\begin{tabular}{ccccc}
\hline- & RL & ISI & ISI/RL & AV ISI \\
\hline 2002 & 56.764 .213 & 2.146 .805 & $3,78 \%$ & $4,63 \%$ \\
2003 & 53.164 .848 & 2.938 .915 & $5,53 \%$ & $6,34 \%$ \\
2004 & 50.623 .360 & 3.200 .714 & $6,32 \%$ & $6,90 \%$ \\
2005 & 56.131 .167 & 3.689 .499 & $6,57 \%$ & $7,95 \%$ \\
2006 & 61.014 .301 & 3.920 .636 & $6,43 \%$ & $8,45 \%$ \\
2007 & 65.471 .424 & 3.830 .250 & $5,85 \%$ & $8,26 \%$ \\
2008 & 65.860 .662 & 4.605 .584 & $6,99 \%$ & $9,93 \%$
\end{tabular}


Balanço social: uma análise comparativa dos indicadores sociais internos e externos das instituições financeiras Caixa e Banco do Brasil 2002 a 2011

Anderson Pires dos Santos, Luciênio Rosa e Silva Júnior

\begin{tabular}{lrrrr}
\hline 2009 & 18.232 .858 & 6.726 .543 & $36,89 \%$ & $14,50 \%$ \\
2010 & 25.561 .532 & 7.496 .393 & $29,33 \%$ & $16,16 \%$ \\
2011 & 27.513 .063 & 7.824 .498 & $28,44 \%$ & $16,87 \%$ \\
Total & $\mathbf{4 8 0 . 3 3 7 . 4 2 8}$ & $\mathbf{4 6 . 3 7 9 . 8 3 7}$ & $\mathbf{9 , 6 6 \%}$ & $\mathbf{1 0 0 , 0 0 \%}$ \\
\hline
\end{tabular}

Fonte: Dados da pesquisa

A Tabela 4 apresenta os dados dos investimentos sociais internos da instituição financeira Banco do Brasil, é evidente a evolução dos valores investidos, seguem um parâmetro de acordo com o crescimento da receita líquida, destaca-se os anos finais, com números expressivos nos percentuais, podendo ser justificado pela incorporação de valores nas contribuições de previdência privada e alterações na metodologia de coleta de dados, conforme NBC T 15, informação encontrada nos relatórios de sustentabilidade do Banco do Brasil. O volume para os investimentos foi de 46.379 .837 milhares de reais, 9,66\% da receita líquida encontrada.

A análise dos dados de forma vertical precisa-se o ano com maior investimento, atestando a evolução ao longo dos anos, onde o ano de 2011 foi o que recebeu mais recursos do total dos investimentos sociais internos para o período.

Tabela 5 - Proporções Receita Líquida/Investimentos Sociais Externos (em milhares)

\begin{tabular}{ccccc}
\hline- & RL & ISE & ISE/RL & ISE \\
\hline 2002 & 56.764 .213 & 2.137 .891 & $3,77 \%$ & $6,82 \%$ \\
2003 & 53.164 .848 & 3.313 .275 & $6,23 \%$ & $10,57 \%$ \\
2004 & 50.623 .360 & 2.935 .982 & $5,80 \%$ & $9,37 \%$ \\
2005 & 56.131 .167 & 4.532 .506 & $8,07 \%$ & $14,46 \%$ \\
2006 & 61.014 .301 & 3.229 .047 & $5,29 \%$ & $10,30 \%$ \\
2007 & 65.471 .424 & 4.186 .592 & $6,39 \%$ & $13,35 \%$ \\
2008 & 65.860 .662 & 5.001 .338 & $7,59 \%$ & $15,95 \%$ \\
2009 & 18.232 .858 & 188.303 & $1,03 \%$ & $0,60 \%$ \\
2010 & 25.561 .532 & 3.327 .205 & $13,02 \%$ & $10,61 \%$ \\
2011 & 27.513 .063 & 2.498 .393 & $9,08 \%$ & $7,97 \%$ \\
Total & $\mathbf{4 8 0 . 3 3 7 . 4 2 8}$ & $\mathbf{3 1 . 3 5 0 . 5 3 2}$ & $\mathbf{6 , 5 3 \%}$ & $\mathbf{1 0 0 , 0 0 \%}$ \\
\hline
\end{tabular}

Fonte: Dados da pesquisa

O volume dos investimentos sociais externos no período foi de 31.350 .532 milhares de reais, 6,53\% do total investidos. Estes dados não apresentam elevadas evoluções, são singulares ou distorcidas. As proporções dos investimentos em relação à receita líquida não acompanham determinada medida, são disformes. 
Balanço social: uma análise comparativa dos indicadores sociais internos e externos das instituições financeiras Caixa e Banco do Brasil 2002 a 2011

Anderson Pires dos Santos, Luciênio Rosa e Silva Júnior

A análise quanto aos dados em relação ao montante dos investimentos, satisfaz a premissa de períodos não evolutivos ou não crescentes, no entanto, na maior parte dos anos analisados os percentuais são próximos, inclusive os anos que situam-se ao meio.

Tabela 6 - Análise dos Componentes ISI e ISE 2002-2012 (em milhares)

\begin{tabular}{lrc}
\hline Investimentos Sociais Internos & \multicolumn{1}{c}{ ISI } & AV \\
\hline Alimentação & 6.678 .391 & $14,40 \%$ \\
Encargos sociais compulsórios & 18.188 .461 & $39,22 \%$ \\
Previdência privada & 5.717 .847 & $12,33 \%$ \\
Saúde & 5.077 .614 & $10,95 \%$ \\
Segurança e medicina no trabalho & 235.917 & $0,51 \%$ \\
Educação & 109.488 & $0,24 \%$ \\
Cultura & 4.160 & $0,01 \%$ \\
Capacitação e desenvolvimento profissional & 701.400 & $1,51 \%$ \\
Creches ou auxílio-creche & 419.608 & $0,90 \%$ \\
Transporte & 72.776 & $0,16 \%$ \\
Participação nos lucros ou resultados & 8.805 .485 & $18,99 \%$ \\
Outros & 368.699 & $0,79 \%$ \\
Total - Indicadores Sociais Internos & 46.379 .837 & $100,00 \%$ \\
& & \\
Investimentos Sociais Externos & ISE & AV \\
Educação & 209.378 & $0,67 \%$ \\
Cultura & 390.320 & $1,25 \%$ \\
Saúde e Saneamento & 27.141 & $0,09 \%$ \\
Esporte & 488.605 & $1,56 \%$ \\
Combate à Fome e Segurança Alimentar & 2.239 .108 & $7,14 \%$ \\
Geração de Trabalho e Renda & 158.970 & $0,51 \%$ \\
Outros & 159.776 & $0,51 \%$ \\
Total das Contribuições para Sociedade & 3.668 .113 & $11,70 \%$ \\
Tributos (excluídos encargos sociais) & 27.682 .426 & $88,30 \%$ \\
Total - Indicadores Sociais Externos & 31.350 .532 & $100,00 \%$ \\
\hline Fonte: Dados da para & &
\end{tabular}

Fonte: Dados da pesquisa

A partir destes resultados, encontramos a existência dos componentes utilizados pelo Banco do Brasil para divulgar suas informações sociais. Os itens com elevada representatividade nos componentes internos são os encargos sociais compulsórios, a participação nos lucros ou resultados e alimentação. Analisando os componentes isoladamente pode-se concluir que a participação nos lucros ou resultados apresenta o maior 
Balanço social: uma análise comparativa dos indicadores sociais internos e externos das instituições financeiras Caixa e Banco do Brasil 2002 a 2011

Anderson Pires dos Santos, Luciênio Rosa e Silva Júnior

percentual da soma dos investimentos, com 18,99\%, pois os encargos são obrigatórios, não satisfazendo os objetivos propostos.

\section{CONSIDERAÇÕES FINAIS}

O trabalho alcançou seu objetivo geral ao discutir os investimentos sociais durante o período analisado, demonstrado em tabelas com percentuais e proporções acerca da receita líquida e os investimentos sociais internos e externos. Pode-se observar que os investimentos sociais nos indicadores internos e externos, apresentam crescimento em relação à receita líquida.

Como resposta ao problema proposto, qual o volume e a evolução dos investimentos sociais realizados nos Indicadores Sociais Internos e Externos das Instituições Financeiras Caixa e Banco do Brasil, com base no Balanço Social no período de 2002 a 2011, nota-se que os volumes para os investimentos sociais internos representam 6,56\% e 9,66\% da receita líquida total do período analisado, para a Caixa e Banco do Brasil, respectivamente. Quanto aos investimentos sociais externos, absorveram 3,09\% para a Caixa e 6,53\% para o Banco do Brasil em relação à receita líquida do período analisado.

De acordo com os objetivos específicos propostos, que é comparar os valores investidos e analisar os componentes dos investimentos sociais internos e externos, compreende-se seu alcance no instante que os encontramos através das demonstrações, assim permite-nos concluir que os componentes são encargos sociais compulsórios, participação nos lucros e resultados e alimentação, isso no ambiente interno e nesta mesma ordem para a Caixa e Banco do Brasil. No ambiente externo, para a Caixa são cultura e esporte, e o Banco do Brasil, combate à fome e segurança alimentar e cultura, conforme o período analisado.

Conforme tabela a seguir podemos concluir e demonstrar claramente a absorção e percentuais dos valores investidos nestes componentes. Para evidenciar efetividade no alcance dos objetivos específicos, a tabela revela os números para entendimento compreensão.

Tabela 7 - Componentes com maiores Investimentos 2002-2012 
Balanço social: uma análise comparativa dos indicadores sociais internos e externos das instituições financeiras Caixa e Banco do Brasil 2002 a 2011

Anderson Pires dos Santos, Luciênio Rosa e Silva Júnior

\begin{tabular}{|c|c|c|c|c|}
\hline \multirow{2}{*}{ Instituição } & \multicolumn{4}{|c|}{ Componentes com maiores Investimentos (2002-2011) \% total dos } \\
investimentos \\
\hline- & Investimentos Sociais Internos & \multicolumn{2}{c|}{ Investimentos Sociais Externos } \\
\hline Caixa & Encargos Sociais & $48,06 \%$ & Cultura & $2,40 \%$ \\
\hline- & Alimentação & $17,07 \%$ & Esporte & $2,11 \%$ \\
\hline- & $\begin{array}{c}\text { Part. nos Lucros e } \\
\text { Resultados }\end{array}$ & $13,57 \%$ & - & - \\
\hline- & & & & \\
\hline Banco do Brasil & Encargos Sociais & $39,22 \%$ & Combate à Fome & $7,14 \%$ \\
\hline- & $\begin{array}{c}\text { Part. Nos Lucros e } \\
\text { Resultados }\end{array}$ & $18,99 \%$ & Esporte & $1,56 \%$ \\
\hline- & Alimentação & $14,40 \%$ & - & - \\
\hline
\end{tabular}

Para futuros trabalhos, sugere-se um estudo mais dedicado aos componentes dos Indicadores Sociais Internos e Externos, analisando os fatos que provocaram as variações encontradas. Ainda uma pesquisa com apenas um indicador e a comparação com demais instituições, inclusive no tocante ao setor público-privado.

\section{REFERÊNCIAS}

Balanço Social. Disponível em: <http://www.balancosocial.org.br>. Acesso em 20 mar 2012.

Banco do Brasil. Disponível em: <http://www.bb.com.br>. Acesso em 30 ago 2012.

Banco Nacional de Desenvolvimento Econômico e Social - BNDES.

<http://www.bndes.gov.br>. Acesso em 23 mar 2012.

Caixa Econômica Federal - CEF. Disponível em: 〈http://www.Caixa.gov.br〉. Acesso em: 24 mar. 2012.

Federação Brasileira de Bancos - FEBRABAN. Disponível em:

<http://www.febraban.org.br>. Acesso em: 23 mar 2012.

Instituto Brasileiro de Análises Sociais e Econômicas - IBASE. Disponível em: <http://www.ibase.br>. Acesso em: 01 mai 2012.

Instituto Ethos. Disponível em: <http://www.ethos.org.br>. Acesso em: 01 mai 2012.

LANZARIN, Jovani. Investimentos sociais e ambientais de uma instituição financeira: evidenciação por meio de Balanço Social. Artigo, Santa Catarina: UFSC, 2011.

NEWLANDS, Junior, Carlos Artur; Sistema Financeiro e Bancário. 2ed. Rio de Janeiro: Elsevir, 2010. 
Balanço social: uma análise comparativa dos indicadores sociais internos e externos das instituições financeiras Caixa e Banco do Brasil 2002 a 2011

Anderson Pires dos Santos, Luciênio Rosa e Silva Júnior

SCOFANO, Claudia Rosana Felisberto e CUNHA, Carlos Henrique Berrini da.

Responsabilidade social em instituições bancárias: uma análise do Balanço Social banco

Bradesco e Itaú - 2001-2007. Artigo, Universidade Federal Rural do Rio de Janeiro: 2011.

SILVA, César Augusto Tibúrcio; FREIRE, Fátima de Souza (orgs.). Balanço social: teoria e prática. São Paulo: Atlas, 2001.

TINOCO, João Eduardo Prudêncio. Balanço social: uma abordagem da transparência e da responsabilidade pública das organizações. 1. Ed - 3 reimpr. - São Paulo : Atlas, 2006. 